\title{
BMJ Open Self-rated chronic conditions and 2-week prevalence in adults in Zhongshan, China: an epidemiological survey
}

\author{
Chunyan Zhu, ${ }^{1}$ Xiaomin Sun, ${ }^{2}$ Qingshan Geng, ${ }^{3}$ Rong Fu, ${ }^{4}$ Hongling Yang, ${ }^{5}$ \\ Wei Jiang ${ }^{6}$
}

To cite: Zhu C, Sun X Geng $Q$, et al. Self-rated chronic conditions and 2-week prevalence in adults in Zhongshan, China: an epidemiological survey. $B M J$ Open 2015:5:e008441. doi:10.1136/bmjopen-2015008441

- Prepublication history for this paper is available online. To view these files please visit the journal online (http://dx.doi.org/10.1136/ bmjopen-2015-008441)

$\mathrm{CZ}$ and XS contributed equally.

Received 8 April 2015 Revised 24 September 2015 Accepted 14 October 2015

CrossMark

For numbered affiliations see end of article.

Correspondence to Dr Qingshan Geng; gengqs2010@163.com

\section{ABSTRACT}

Objective: To examine the association between behavioural factors and the risk of chronic conditions and 2-week prevalence.

Design: This was a cross-sectional survey. Setting: The study was conducted in Zhongshan, China.

Participants: A multistage clustering sampling method was used to select a representative sample of residents from the household registration system between July and September 2011. The overall sample replacement rate was $9.4 \%$, and the final sample included 43028 individuals.

Outcome measures: Chronic conditions and 2-week prevalence.

Results: $4979(11.6 \%)$ of the participants reported having at least one chronic condition, 1067 (2.5\%) had two or more concurrent chronic conditions, and 6830 $(15.9 \%)$ reported having at least one disease in a 2week recall period. The most common chronic condition was primary hypertension, which was reported by $6.8 \%$ of participants. Logistic regression models demonstrated that the main factors for having a chronic condition and 2-week prevalence were older age ( $\geq 65$ years of age; $O R \quad 44.91,95 \% \mathrm{Cl} 33.05$ to 61.03; and OR 12.71, $95 \% \mathrm{Cl} 10.44$ to 15.46 , respectively), obesity (OR $3.00,95 \% \mathrm{Cl} 2.63$ to 3.42 ; and $\mathrm{OR} 2.50,95 \% \mathrm{Cl} 2.22$ to 2.82 , respectively) and being a former smoker (OR $3.02,95 \% \mathrm{Cl} 2.54$ to 3.58 ; and $\mathrm{OR} 3.24,95 \% \mathrm{Cl} 2.74$ to 3.82 , respectively).

Conclusions: This study suggests that older age, obesity and unhealthy behaviours are high-risk factors for poorer health status among the residents of Zhongshan, China. The present findings highlight the importance of recognising and managing harmful behaviours in order to improve health.

\section{INTRODUCTION}

Since 1990, there has been a substantial epidemiological shift away from communicable diseases in children to more non-communicable diseases in adults. ${ }^{1}$

\section{Strengths and limitations of this study}

- Our findings from a large representative sample will help improve our understanding of health status in this region of the country.

- Our findings will be useful for implementing further health education and behavioural interventions.

- Causal relationships cannot be identified in a cross-sectional study.

- Recall bias may exist and all data except weight and height were collected by self-report.

A relatively small number of modifiable behavioural risk factors, including tobacco smoking, excessive drinking, physical inactivity, unhealthy diet and alcohol use, are major contributors to the development of adult chronic diseases. ${ }^{1-3}$ The risk of adverse health outcomes increases with the number of unhealthy behaviours. ${ }^{4}$ Studies have shown that chronic disease accounts for the majority of deaths in low-, middle- and highincome countries. ${ }^{5}{ }^{6}$ Self-rated health and morbidity are important indices of health and have particular relevance for public health. ${ }^{7}$ Previous studies have investigated how risk behaviours interact with related factors among adolescents and adults in developed countries. ${ }^{89}$

By the end of 2010 , more than $97 \%$ of residents were covered by the New Rural Cooperative Medical System (NRCMS) launched by the Chinese Government in 2003. Implementation of NRCMS and the dramatic socioeconomic growth during recent years have greatly improved general health. However, health inequalities among residents with different socioeconomic and geographical characteristics are increasing. Those inequalities are considered a serious public health problem and reducing 
inequalities has been recognised as a major objective of healthcare policies in China. At the same time, as a result of rapid economic development and improved disease prevention and control in recent decades, China has undergone an epidemiological transition, so that the greatest problems are now due to noncommunicable chronic diseases. ${ }^{10}$

Chronic diseases have become the leading cause of morbidity and mortality, as related behavioural risk factors have changed dramatically in China. ${ }^{11}$ Consequently, 2-week prevalence, an index of health service need and one of the morbidity indicators used to investigate inequalities in health status, also rose in China (from 143 per thousand population in 2003 to 189 per thousand population in 2008), with most of the rise due to increased chronic diseases. However, medical treatment can be expensive and difficult to obtain. As the burden of chronic diseases and 2-week prevalence increases, there are substantial but preventable increases in morbidity and mortality. Many studies have investigated lifestyle health-related behavioural risk factors and their potential correlates in China. ${ }^{3}{ }^{12}$ Previous reports and surveillance of major chronic diseases, especially obesity, overweight and hypertension, revealed that the prevalence of chronic risk factors in adults was high but not increasing in urban areas. ${ }^{12}{ }^{13}$ Notwithstanding the enormous burden of chronic diseases, few studies have focused on the relationship between multiple behavioural risk factors and self-rated chronic conditions as well as 2-week prevalence rate in China. Communityand population-based programmes to prevent risky behaviours may be an effective strategy.

The purpose of this study was to determine the prevalence of self-rated chronic conditions and 2-week prevalence among different socioeconomic and geographical groups, as well as the relationship with various behavioural risk factors in Zhongshan, China. The findings will improve our understanding of health status disparities in this region of the country.

\section{METHODS}

\section{Study area and population}

This study was conducted in Zhongshan, which was one of the cities that underwent economic policy reform and was opened to foreign trade in the 1980s. Zhongshan is located at the southern tip of the Chinese mainland on the eastern bank of the mouth of the Pearl River and occupies an area of $1800 \mathrm{~km}^{2}$; it had a population of 1.4 million in 2012. In less than 30 years, Zhongshan, a traditional agricultural town, has grown into a modern city. Lifestyle and dietary changes, including decreased physical activity and increased consumption of high-fat foods, are associated with a high prevalence of chronic disease.

Permanent residents were selected to participate in the study according to the following criteria: (1) having permanent household registration and being 18 years of age or older, (2) living in Zhongshan when the study was carried out, and (3) able to complete the questionnaire. The protocol for this study was approved by the ethics review committees of Guangzhou Medical University, and all study participants provided voluntary signed informed consent.

\section{Study design}

This study was conducted from July to September 2011 using a cross-sectional design. A multistage clustering sampling method was used to select a representative sample of residents from the household registration system. First, 30\% of streets or villages were randomly sampled from each of the 24 districts or towns in Zhongshan (for a total of 292 streets or villages). Then, $50 \%$ of households were randomly sampled from the first sampling stage. All family members meeting the inclusion criteria were eligible to participate. In order to guarantee an adequate sample size, when interviewers could not contact a sampled subject after three attempts, a substitute with a similar household structure as the originally sampled family was selected. The overall sample replacement rate among the 19087 households identified was $9.4 \%(1795 / 19087)$. A total of 49119 individuals were selected, and 43028 completed data collection (response rate: $87.6 \%$ ).

\section{Data collection}

Information on demographics, behavioural factors, chronic diseases and 2-week prevalence was obtained via face-to-face interview by the data collectors in the participants' homes using structured questionnaires. Standard procedures were established to guide the recruitment, training and supervision of these data collectors, who underwent training to improve their skills and reduce inter and intra-collector variability.

Smoking status was determined by self-report with the question 'Do you currently use any tobacco, such as cigarettes or pipes?' Participants who replied that they smoked 'every day' or on 'some days', were classified as current smokers. Those who replied 'no' were classified as non-current smokers. Alcohol consumption was assessed by asking participants if they were non-drinkers or occasional or regular drinkers. Those who drank alcohol were also asked about the number of days over the past 2 weeks when they had drunk alcohol and how many drinks they had consumed on each occasion. 'Non-drinkers' and 'occasional drinkers' were classified as non-drinkers.

Salted food intake and smoked food intake were assessed by asking whether or not the respondent made a conscious effort to avoid eating such foods. Salted food included pickled vegetables, salted fish, salted fish roe, etc, while smoked food included smoked meat, smoked fish, etc.

Exercise was assessed by asking participants if they had done any exercise or participated in any sports or physical activities over the previous 2 weeks. They were also 
asked how many times they had exercised in the previous 2 weeks. Physical inactivity was defined as exercising four times or fewer over the past 2 weeks. The number of hours of daily sitting time ( 0 to $<8 \mathrm{~h}, \geq 8 \mathrm{~h}$ /day) was also recorded.

The heights and weights of all respondents were measured, and body mass index (BMI) was computed according to the criteria of the National Health and Family Planning Commission of the People's Republic of China to determine overweight or obesity (BMI $\geq 24)$. The presence of chronic diseases was determined by means of a selfreport form that provided a checklist of chronic illnesses taken from the International Classification of Diseases, 10th Revision (ICD-10). During the interview, participants were asked whether they had any chronic health problems which had been confirmed by a medical doctor. Information on 2-week prevalence was obtained by means of a self-report form that provided a checklist of physical illnesses and symptoms. During the interview, participants were asked whether they had experienced any physical health problems, including infectious diseases and chronic non-communicable diseases, over the previous 2 weeks. If they had physical health problems, participants were asked whether they had received treatment from a medical doctor or had self-treated. The 2-week prevalence was calculated as (number of cases person-time that occurred over the previous 2 weeks)/(number of people in the population during this period) $\times 100 \%$. The 2-week non-

\begin{tabular}{|c|c|c|}
\hline & $\mathbf{n}$ & Per cent \\
\hline \multicolumn{3}{|l|}{ Age (year) } \\
\hline Mean \pm SD & $42.8 \pm 16.5$ & \\
\hline Min-max & $18-104$ & \\
\hline \multicolumn{3}{|l|}{ Age group (years) } \\
\hline $18-24$ & 7066 & 16.4 \\
\hline $25-34$ & 7993 & 18.6 \\
\hline $35-44$ & 9290 & 21.6 \\
\hline $45-54$ & 7961 & 18.5 \\
\hline $55-64$ & 6252 & 14.5 \\
\hline$\geq 65$ & 4466 & 10.4 \\
\hline \multicolumn{3}{|l|}{ Sex } \\
\hline Male & 21789 & 50.6 \\
\hline Female & 21239 & 49.4 \\
\hline \multicolumn{3}{|l|}{ Marital status ${ }^{*}$} \\
\hline Unmarried & 8849 & 20.8 \\
\hline Married & 30953 & 72.6 \\
\hline Widowed/separated/divorced & 2815 & 6.6 \\
\hline \multicolumn{3}{|l|}{ Educational level* } \\
\hline Illiterate/primary & 27624 & 64.9 \\
\hline Secondary & 10682 & 25.1 \\
\hline University & 4252 & 10.0 \\
\hline \multicolumn{3}{|l|}{ Medical insurance } \\
\hline None & 0 & 0.0 \\
\hline Yes & 43028 & 100.0 \\
\hline
\end{tabular}

clinical visit rate was calculated as (number of cases persontime without medical treatment or with self-treatment that occurred over the previous 2 weeks)/(number of cases during this period) $\times 100 \%$. We collected data on all physical health problems reported by participants, and discuss the five most common in the Results section.

Demographic characteristics included age, sex, education (illiterate, primary school, secondary school, and university or above), marital status (single, married, separated/divorced/widowed) and medical insurance status.

\section{Data analysis}

The prevalence of selected chronic conditions and 2week prevalence were calculated. After descriptive analysis, logistic regression analyses were used to determine the influence of independent variables on the dependent variables of chronic conditions or 2-week prevalence. This was initially done as a univariate analysis, then as a multivariable analysis using a forward stepwise method. A p value of $<0.05$ with a $95 \%$ CI for the population OR that excluded the null value of 1 was considered statistically significant. All analyses were conducted with SPSS V.13.0 (SPSS Inc., Chicago, Illinois, USA).

Table 2 Prevalence of the five leading chronic conditions and 2-week prevalence $(n=43028)$

\begin{tabular}{|c|c|c|}
\hline & $\mathbf{n}$ & Per cent \\
\hline \multicolumn{3}{|l|}{ Chronic condition* } \\
\hline Any diagnosis & 4979 & 11.6 \\
\hline Primary hypertension & 2913 & 6.8 \\
\hline Diabetes mellitus & 479 & 1.1 \\
\hline Coronary heart disease & 308 & 0.7 \\
\hline Chronic gastritis & 259 & 0.6 \\
\hline Stroke & 173 & 0.4 \\
\hline \multicolumn{3}{|l|}{ Number of chronic disease(s) } \\
\hline 1 & 3912 & 9.1 \\
\hline$\geq 2$ & 1067 & 2.5 \\
\hline \multicolumn{3}{|l|}{ Two-week prevalence } \\
\hline Any diagnosis & 6830 & 15.9 \\
\hline Hypertension & 2913 & 6.8 \\
\hline Upper respiratory infection & 825 & 1.9 \\
\hline Diabetes mellitus & 479 & 1.1 \\
\hline Coronary heart disease & 308 & 0.7 \\
\hline Chronic gastritis & 259 & 0.6 \\
\hline \multicolumn{3}{|l|}{ Classification of diseases (ICD-10) } \\
\hline Chronic diseases & 4979 & 11.6 \\
\hline Non-chronic diseases & 1851 & 4.3 \\
\hline Two-week non-clinical visit† rateł & 1607 & 23.5 \\
\hline \multicolumn{3}{|c|}{$\begin{array}{l}{ }^{*} \text { Data on chronic diseases were obtained by means of a } \\
\text { self-report form that provided a checklist of chronic illnesses taken } \\
\text { from the International Classification of Diseases, } 10 \text { th Revision } \\
\text { (ICD-10). } \\
\text { †Non-clinical visits to a medical centre (eg, for educational or } \\
\text { information purposes). } \\
\text { †Among } 6830 \text { individuals who reported any diagnosed disease in } \\
\text { the past } 2 \text { weeks. }\end{array}$} \\
\hline
\end{tabular}




\section{RESULTS}

\section{Sociodemographic factors}

The overall mean age of the 43028 residents $(50.6 \%$ male, $49.4 \%$ female) who completed the surveys was 42.8 (SD 16.5) years, $64.9 \%$ were illiterate or had only received primary education, and all had medical insurance (table 1).

\section{Prevalence of chronic conditions and 2-week prevalence}

Of 43028 participants, $4979(11.6 \%)$ reported having at least one chronic condition, while 1067 (2.5\%) had two or more concurrent diagnosed chronic conditions (table 2). The most common of the five leading chronic conditions was hypertension, which was reported by $6.8 \%$ of participants. The prevalence of the other four leading chronic conditions ranged from $0.4 \%$ to $6.8 \%$.

Approximately $16 \%$ of respondents reported having at least one diagnosed disease during the 2-week recall period, the most common being hypertension. Overall, $11.6 \%$ of diagnosed respondents reported they had a chronic disease and $4.3 \%$ a non-chronic disease, while $23.5 \%$ of respondents in general reported that they had not visited a medical practitioner (table 2).

Stroke was more common in men than in women, while upper respiratory infections were much more prevalent in women, which resulted in a substantially higher 2-week prevalence of any diagnosis and a greater prevalence of non-chronic diseases in women (table 3).
The prevalence of chronic conditions and 2-week prevalence were much higher in older adults ( $\geq 55$ years) than in young (18-44 years) or middle-aged adults (45-54 years). Young and middle-aged adults had higher rates of 2-week non-clinical visits to a medical centre (eg, for educational or information purposes). (table 4).

With the exception of physical inactivity, the prevalence of chronic conditions and 2-week prevalence were much higher in adults with behavioural risk factors, such as obesity, current smoking, regular drinking, sitting for $>8 \mathrm{~h} /$ day, and consuming salted and smoked food than in adults without these risk factors (all $\mathrm{p}<0.01$; table 5). However, the evidence showed negative associations between physical inactivity and both chronic conditions and reported 2-week prevalence.

\section{Multivariable logistic regression}

Logistic regression analysis was performed with sociodemographic variables and unhealthy behaviours as covariates (table 6). Any diagnosis of a chronic condition and 2-week prevalence were independently associated with being female, older (vs 18-24 years), widowed/separated/divorced (vs never married), obese, sitting for $>8 \mathrm{~h} /$ day, consuming smoked food and consuming salted food. Diagnosed chronic conditions and 2-week prevalence were much less common in individuals with a secondary education (vs those who were illiterate or had only primary education) and physically inactive

Table 3 Comparison of the prevalence of chronic diseases and 2-week prevalence

\begin{tabular}{|c|c|c|c|c|}
\hline & $\begin{array}{l}\text { Male } \\
(n=21789, \%)\end{array}$ & $\begin{array}{l}\text { Female } \\
(\mathrm{n}=21239, \%)\end{array}$ & $\begin{array}{l}\text { Female:male OR } \\
(95 \% \mathrm{Cl})\end{array}$ & p Value \\
\hline \multicolumn{5}{|l|}{ Chronic disease $^{*}$} \\
\hline Any diagnosis & 11.5 & 11.6 & $1.01(0.96$ to 1.08$)$ & 0.666 \\
\hline Primary hypertension & 6.6 & 6.9 & $1.05(0.97$ to 1.13$)$ & 0.248 \\
\hline Diabetes mellitus & 1.0 & 1.2 & 1.15 (0.96 to 1.38$)$ & 0.128 \\
\hline Coronary heart disease & 0.7 & 0.8 & 1.14 (0.91 to 1.43$)$ & 0.255 \\
\hline Chronic gastritis & 0.5 & 0.7 & $1.21(0.95$ to 1.54$)$ & 0.130 \\
\hline Stroke & 0.5 & 0.3 & $0.52(0.38$ to 0.71$)$ & $<0.001$ \\
\hline \multicolumn{5}{|l|}{ Number of chronic diseases } \\
\hline 1 & 9.0 & 9.2 & $1.01(0.93$ to 1.07$) \dagger$ & 0.714 \\
\hline$\geq 2$ & 2.6 & 2.4 & & \\
\hline \multicolumn{5}{|l|}{ Two-week prevalence } \\
\hline Any diagnosis & 15.4 & 16.3 & 1.07 (1.01 to 1.12$)$ & 0.015 \\
\hline Hypertension & 6.6 & 6.9 & 1.05 (0.97 to 1.13$)$ & 0.248 \\
\hline Upper respiratory infection & 1.7 & 2.1 & $1.22(1.06$ to 1.40$)$ & 0.005 \\
\hline Diabetes mellitus & 1.0 & 1.2 & $1.15(0.96$ to 1.38$)$ & 0.128 \\
\hline Coronary heart disease & 0.7 & 0.8 & $1.14(0.91$ to 1.43$)$ & 0.255 \\
\hline Chronic gastritis & 0.5 & 0.7 & $1.21(0.95$ to 1.54$)$ & 0.130 \\
\hline \multicolumn{5}{|l|}{ Classification of diseases (ICD-10) } \\
\hline Chronic diseases & 11.5 & 11.6 & $1.02(0.96$ to 1.08$) \ddagger$ & 0.488 \\
\hline Non-chronic diseases & 3.9 & 4.7 & 1.20 (1.09 to 1.31$) \ddagger$ & $<0.001$ \\
\hline Two-week non-clinical visit§ rate & 24.3 & 22.7 & $0.92(0.82$ to 1.02$)$ & 0.123 \\
\hline
\end{tabular}


Table 4 Comparison of the prevalence of the main chronic conditions and 2-week prevalence by age group

\begin{tabular}{|c|c|c|c|c|c|c|c|}
\hline & \multicolumn{6}{|l|}{ Age } & \multirow[b]{2}{*}{ OR (95\% Cl) } \\
\hline & $\begin{array}{l}18-24 \\
(n=7066) \\
(\%)\end{array}$ & $\begin{array}{l}\begin{array}{l}25-34 \\
(n=7993) \\
(\%)\end{array} \\
\end{array}$ & $\begin{array}{l}35-44 \\
(n=9290) \\
(\%)\end{array}$ & $\begin{array}{l}45-54 \\
(n=7961) \\
(\%)\end{array}$ & $\begin{array}{l}55-64 \\
(n=6252) \\
(\%)\end{array}$ & $\begin{array}{l}\geq 65 \\
(n=4466) \\
(\%)\end{array}$ & \\
\hline \multicolumn{8}{|l|}{ Chronic condition† } \\
\hline Any diagnosis & 1.2 & 1.8 & 4.7 & 11.3 & 24.0 & 42.9 & 2.45 (2.39 to 2.51$)^{\star}$ \\
\hline Primary hypertension & 0.1 & 0.2 & 1.3 & 5.7 & 15.2 & 30.8 & 3.13 (3.01 to 3.25$)^{*}$ \\
\hline Diabetes mellitus & 0.0 & 0.0 & 0.3 & 0.9 & 2.8 & 4.5 & $2.55(2.35 \text { to } 2.77)^{\star}$ \\
\hline $\begin{array}{l}\text { Coronary heart } \\
\text { disease }\end{array}$ & 0.1 & 0.1 & 0.1 & 0.5 & 1.2 & 3.8 & $2.87(2.55 \text { to } 3.19)^{\star}$ \\
\hline Chronic gastritis & 0.2 & 0.2 & 0.4 & 0.9 & 1.1 & 1.2 & $1.53(1.40 \text { to } 1.66)^{\star}$ \\
\hline Stroke & 0.0 & 0.0 & 0.0 & 0.2 & 0.7 & 2.4 & $3.77(3.14 \text { to } 4.53)^{*}$ \\
\hline \multicolumn{8}{|l|}{ Two-week prevalence } \\
\hline Any diagnosis & 4.7 & 4.9 & 8.7 & 16.9 & 28.8 & 48.4 & \multirow{2}{*}{$1.96(1.92 \text { to } 2.00)^{\star}$} \\
\hline Hypertension & 0.1 & 0.2 & 1.3 & 5.7 & 15.2 & 30.8 & \\
\hline $\begin{array}{l}\text { Upper respiratory } \\
\text { infection }\end{array}$ & 1.7 & 1.6 & 1.7 & 2.3 & 2.2 & 2.4 & \multirow[t]{3}{*}{$1.10(1.05 \text { to } 1.15)^{\star}$} \\
\hline Diabetes mellitus & 0.0 & 0.0 & 0.3 & 0.9 & 2.8 & 4.5 & \\
\hline $\begin{array}{l}\text { Coronary heart } \\
\text { disease }\end{array}$ & 0.1 & 0.1 & 0.1 & 0.5 & 1.2 & 3.8 & \\
\hline Chronic gastritis & 0.2 & 0.2 & 0.4 & 0.9 & 1.1 & 1.2 & \\
\hline $\begin{array}{l}\text { Two-week non-clinical } \\
\text { visitł rate }\end{array}$ & 25.3 & 32.1 & 27.7 & 27.8 & 23.7 & 17.4 & $0.86(0.83$ to 0.90$)$ \\
\hline $\begin{array}{l}\text { " } \mathrm{p}<0.01 . \\
\text { †Data on chronic diseases } \\
\text { International Classification } \\
\text { †Non-clinical visits to a med }\end{array}$ & 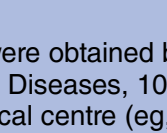 & & 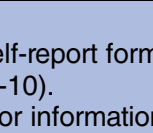 & & & & en from the \\
\hline
\end{tabular}

(vs physically active). The 2-week prevalence was also independently associated with being a current or former smoker and being a regular drinker. Moreover, any diagnosis of a chronic condition was more common in former smokers (vs never smokers). Unexpectedly, being a current smoker (vs never smoker) and being a regular drinker (vs non-drinker) were not significantly associated with chronic condition diagnoses.

\section{DISCUSSION}

This study considered a large representative sample to examine the associations between demographic characteristics, behavioural factors, chronic conditions and 2-week prevalence. Results showed that $11.6 \%$ of the population had at least one chronic condition, $2.5 \%$ had two or more concurrent diagnoses, and approximately $16 \%$ reported at least one disease in a 2-week recall

Table 5 Prevalence of unhealthy behaviours for chronic conditions and 2-week prevalence

\begin{tabular}{|c|c|c|c|c|}
\hline Behaviours & No (\%) & Yes (\%) & Yes:no OR (95\% Cl) & p Value \\
\hline Chronic condition (any diagnosis) ${ }^{*}$ & $\mathrm{n}=38049$ & $\mathrm{n}=4979$ & & \\
\hline Obesity & 3.0 & 9.3 & 3.37 (3.01 to 3.77 ) & $<0.001$ \\
\hline Current smoker & 19.7 & 24.3 & $1.31(1.22$ to 1.41$)$ & $<0.001$ \\
\hline Regular drinker & 4.7 & 8.0 & 1.75 (1.56 to 1.96$)$ & $<0.001$ \\
\hline Physical inactivity & 67.2 & 63.6 & 0.85 (0.80 to 0.91$)$ & $<0.001$ \\
\hline Sitting for $>8 \mathrm{~h} /$ day & 13.7 & 17.9 & 1.38 (1.28 to 1.49$)$ & $<0.001$ \\
\hline Salted food consumption & 7.3 & 11.8 & $1.70(1.55$ to 1.87$)$ & $<0.001$ \\
\hline Smoked food consumption & 4.7 & 6.4 & 1.39 (1.23 to 1.57$)$ & $<0.001$ \\
\hline Two-week prevalence & $\mathrm{n}=36198$ & $n=6830$ & & \\
\hline Obesity & 2.9 & 7.9 & 2.88 (2.58 to 3.20$)$ & $<0.001$ \\
\hline Current smoker & 19.4 & 24.8 & 1.38 (1.29 to 1.46$)$ & $<0.001$ \\
\hline Regular drinker & 4.5 & 8.1 & 1.85 (1.67 to 2.04$)$ & $<0.001$ \\
\hline Physical inactivity & 67.3 & 64.1 & 0.87 (0.83 to 0.92$)$ & $<0.001$ \\
\hline Sitting for $>8 \mathrm{~h} /$ day & 13.7 & 16.9 & $1.29(1.20$ to 1.38$)$ & $<0.001$ \\
\hline Salted food consumption & 7.2 & 11.2 & 1.64 (1.50 to 1.78$)$ & $<0.001$ \\
\hline Smoked food consumption & 4.6 & 6.4 & 1.43 (1.28 to 1.59$)$ & $<0.001$ \\
\hline
\end{tabular}


Table 6 Multivariable logistic regression model of explanatory variables against chronic conditions $\dagger$ and 2-week prevalence $(n=43028)$

\begin{tabular}{|c|c|c|}
\hline & $\begin{array}{l}\text { Chronic conditions, } \\
\text { adjusted OR }(95 \% \mathrm{Cl}) \neq\end{array}$ & $\begin{array}{l}\text { Two-week prevalence, } \\
\text { adjusted OR }(95 \% \mathrm{CI}) \ddagger\end{array}$ \\
\hline \multicolumn{3}{|l|}{ Age group (years) } \\
\hline $18-24$ & 1.00 (Reference) & 1.00 (Reference) \\
\hline $25-34$ & $1.47(1.07 \text { to } 2.01)^{*}$ & $0.97(0.80$ to 1.16$)$ \\
\hline $35-44$ & $3.72(2.73 \text { to } 5.06)^{\star \star}$ & $1.61(1.33 \text { to } 1.95)^{\star \star}$ \\
\hline $45-54$ & $9.05(6.67 \text { to } 12.29)^{\star \star}$ & $3.25(2.68 \text { to } 3.94)^{\star \star}$ \\
\hline $55-64$ & $21.04(15.50 \text { to } 28.55)^{\star \star}$ & $6.04(4.98 \text { to } 7.33)^{\star *}$ \\
\hline$\geq 65$ & $44.91(33.05 \text { to } 61.03)^{\star \star}$ & $12.71(10.44 \text { to } 15.46)^{\star \star}$ \\
\hline \multicolumn{3}{|c|}{ 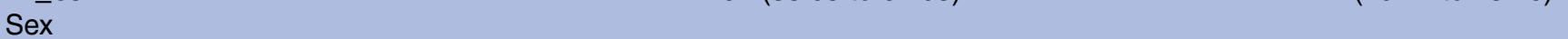 } \\
\hline Male & 1.00 (Reference) & 1.00 (Reference) \\
\hline Female & $1.12(1.03 \text { to } 1.21)^{\star \star}$ & $1.27(1.19 \text { to } 1.36)^{\star \star}$ \\
\hline \multicolumn{3}{|l|}{ Marital status } \\
\hline Never married & 1.00 (Reference) & 1.00 (Reference) \\
\hline Married & $0.98(0.80$ to 1.20$)$ & $1.06(0.91$ to 1.24$)$ \\
\hline Widowed/separated/divorced & $1.43(1.15 \text { to } 1.79)^{\star \star}$ & $1.56(1.31 \text { to } 1.86)^{\star \star}$ \\
\hline \multicolumn{3}{|l|}{ Educational level } \\
\hline Illiterate/primary & 1.00 (Reference) & 1.00 (Reference) \\
\hline Secondary & $0.77(0.69 \text { to } 0.88)^{\star \star}$ & $0.84(0.76 \text { to } 0.92)^{\star *}$ \\
\hline University & 0.89 (0.72 to 1.08$)$ & $0.87(0.76$ to 1.01$)$ \\
\hline \multicolumn{3}{|l|}{ Obesity } \\
\hline No & 1.00 (Reference) & 1.00 (Reference) \\
\hline Yes & $3.00(2.63 \text { to } 3.42)^{\star *}$ & $2.50(2.22 \text { to } 2.82)^{\star *}$ \\
\hline \multicolumn{3}{|l|}{ Smoking status } \\
\hline Never smoker & 1.00 (Reference) & 1.00 (Reference) \\
\hline Current smoker & $1.06(0.97$ to 1.15$)$ & $1.21(1.12 \text { to } 1.31)^{\star \star}$ \\
\hline Former smoker & $3.02(2.54 \text { to } 3.58)^{\star *}$ & $3.24(2.74 \text { to } 3.82)^{\star *}$ \\
\hline \multicolumn{3}{|l|}{ Regular drinker } \\
\hline No & 1.00 (Reference) & 1.00 (Reference) \\
\hline Yes & $1.05(0.92$ to 1.20$)$ & $1.18(1.05 \text { to } 1.32)^{\star *}$ \\
\hline \multicolumn{3}{|l|}{ Physical inactivity } \\
\hline No & 1.00 (Reference) & 1.00 (Reference) \\
\hline Yes & $0.78(0.73 \text { to } 0.84)^{\star *}$ & $0.80(0.75 \text { to } 0.85)^{\star *}$ \\
\hline \multicolumn{3}{|l|}{ Sitting for $>8 \mathrm{~h} /$ day } \\
\hline No & 1.00 (Reference) & 1.00 (Reference) \\
\hline Yes & $1.16(1.06 \text { to } 1.27)^{\star \star}$ & $1.11(1.02 \text { to } 1.20)^{*}$ \\
\hline \multicolumn{3}{|l|}{ Salted food consumption } \\
\hline No & 1.00 (Reference) & 1.00 (Reference) \\
\hline Yes & $1.49(1.34 \text { to } 1.66)^{\star *}$ & $1.44(1.30 \text { to } 1.58)^{* *}$ \\
\hline \multicolumn{3}{|l|}{ Smoked food consumption } \\
\hline No & 1.00 (Reference) & 1.00 (Reference) \\
\hline Yes & $1.22(1.06 \text { to } 1.41)^{\star \star}$ & $1.29(1.14 \text { to } 1.46)^{\star \star}$ \\
\hline
\end{tabular}

period. The most common disease was hypertension $(6.8 \%)$. The chronic disease rate, 2-week prevalence and prevalence of hypertension in the study were similar to the $15.7 \%, 18.9 \%$ and $5.49 \%$, respectively, reported in the 2012 Chinese health statistics summary, while the 2-week rate of non-clinical visits to a medical centre (eg, for educational or information purposes) $(23.5 \%)$ was higher than the national rate of people who are sick but do not visit a clinic/doctor $(3.82 \%) .{ }^{14}$

Our study identified those adults who may be vulnerable to chronic conditions and 2-week prevalence: they were more likely to be female, middle-aged or older ( $\geq 35$ years), have a low educational level, be previously married (widowed/separated/divorced) and obese. Most of the findings are consistent with previous reports. ${ }^{3} 1213$

Hypertension was the most frequently reported chronic disease. This illustrates the importance of addressing factors influencing risk for hypertension in these communities. Lower educational level, as a proxy for socioeconomic status, and obesity were significantly more prevalent among participants who reported having chronic diseases than those who did not. Maintaining a 
healthy lifestyle, including a healthy diet and regular physical activity, is an effective approach for preventing and managing hypertension. ${ }^{15} 16$

Existing evidence indicates that the risk of chronic diseases increases exponentially with age; elderly participants tended to report poorer health and a higher prevalence of chronic diseases. ${ }^{17}{ }^{18}$ In this study, the prevalence of chronic disease and 2-week prevalence increased with age, with a higher prevalence of both found in respondents aged 65 and older.

In China, many people are generally unaware of the impact of unhealthy behaviours, for instance, smoking, excessive alcohol intake, physical inactivity and poor dietary habits. ${ }^{12}$ Most adults had at least two behavioural risk factors, while a previous study reported a strong possibility that those who self-reported being free of chronic diseases would later develop such conditions. ${ }^{3}$ Our results indicate that being obese, a former smoker, a regular drinker, sitting for $>8 \mathrm{~h} /$ day, and consuming salted and smoked foods were associated with having a chronic disease and 2-week prevalence. In addition, being a current smoker was related to increased chronic diseases but not with 2-week prevalence. This result is in line with personal behaviour in China: most people smoke, but cease if they have health problems.

Physical inactivity was previously reported to be a risk factor for chronic disease; ${ }^{3}{ }^{19}$ however, in our study it showed a negative association with chronic disease prevalence. This might be because participants with chronic diseases (especially hypertension and diabetes mellitus) may change their unhealthy behaviours and begin to exercise. Behavioural risk factors can vary over time, so a combination of multiple interventions addressing the full range of risk factors for chronic disease and morbidity, could generate larger health gains than a single intervention, often with a favourable cost-effective profile. ${ }^{20}$

On the other hand, health inequalities as a result of chronic disease have become very challenging in China as the social determinants of health become more inequitable. ${ }^{10}{ }^{11}$ In our study, young to middle-aged adults experiencing diagnosable disorders in the past 2 weeks may disproportionately fail to seek treatment because of lack of knowledge (thinking the condition is not serious or that there are no effective treatments) or lack of time. These disparities must be considered when planning efforts to promote health and prevent and control chronic conditions in China.

Several limitations in the study warrant comment. A limitation of cross-sectional studies is that causal relationships cannot be identified. In addition, most data in this study were self-reported, which could be a source of bias. Also, recall bias may have influenced our results, as all data except weight and height were collected by selfreport. However, our results for well-established factors, the rate of chronic diseases, and 2-week prevalence are consistent with the literature.

Despite these limitations, the data in the present study are as complete as possible, and we were able to identify factors associated with the risk of chronic disease and 2-week prevalence.

\section{CONCLUSIONS}

In conclusion, obesity, current smoker status, regular alcohol use, sitting for $>8 \mathrm{~h} /$ day, and salted and smoked food consumption are associated with increased risks for chronic disease and 2-week prevalence. The results highlight the necessity to encourage comprehensive and integrated public health intervention strategies that target multiple behavioural factors.

\section{Author affiliations}

${ }^{1}$ Department of Prevention Medicine, School of Public Health, Guangzhou Medical University, Guangzhou, China

${ }^{2}$ School of Traditional Chinese Medicine, Southern Medical University, Guangzhou, China

${ }^{3}$ Guangdong General Hospital, Guangdong Academy of Medical Science, Guangzhou, China

${ }^{4}$ School of Public Health, Sun Yat-Sen University, Guangzhou, China

${ }^{5}$ Laboratory Department, Guangzhou Women and Children's Medical Centre, Guangzhou, China

${ }^{6}$ Department of Internal Medicine, Department of Psychiatry and Behavioral Sciences, Duke University Medical Center, Durham, North Carolina, USA

Acknowledgements We are grateful to the staff of Zhongshan health department for assisting with data collection. We thank Medjaden Bioscience Limited who provided medical writing services.

Contributors All authors contributed to the writing of this manuscript and revised it for intellectual content. CZ directed study implementation, including quality assurance and control, and drafting the article. XS analysed and interpreted the data. QG designed the study and reviewed the article. RF designed the analytical strategy and reviewed the article. HY helped to supervise the field activities and prepared the discussion sections of the text. WJ designed the analytical strategy and helped to conduct the literature review.

Competing interests None declared.

Funding This study was supported by the Science and Technology Fund of Guangdong Province (2013A032500008).

Patient consent Obtained.

Provenance and peer review Not commissioned; externally peer reviewed.

Data sharing statement No additional data are available.

Open Access This is an Open Access article distributed in accordance with the Creative Commons Attribution Non Commercial (CC BY-NC 4.0) license, which permits others to distribute, remix, adapt, build upon this work noncommercially, and license their derivative works on different terms, provided the original work is properly cited and the use is non-commercial. See: http:// creativecommons.org/licenses/by-nc/4.0/

\section{REFERENCES}

1. Lim SS, Vos T, Flaxman AD, et al. A comparative risk assessment of burden of disease and injury attributable to 67 risk factors and risk factor clusters in 21 regions, 1990-2010: a systematic analysis for the Global Burden of Disease Study 2010. Lancet 2012;380:2224-60.

2. Lopez AD, Mathers CD, Ezzati M, et al. Global burden of disease and risk factors. New York: Oxford University Press, 2006.

3. Li Y, Zhang M, Jiang $\mathrm{Y}$, et al. Co-variations and clustering of chronic disease behavioral risk factors in China: China Chronic Disease and Risk Factor Surveillance, 2007. PLOS ONE 2012;7:e33881.

4. Meng L, Maskarinec G, Lee J, et al. Lifestyle factors and chronic diseases: application of a composite risk index. Prev Med 1999;29:296-304. 
5. Lopez AD, Mathers CD, Ezzati M, et al. Global and regional burden of disease and risk factors, 2001: systematic analysis of population health data. Lancet 2006;367:1747-57.

6. Strong K, Mathers C, Leeder S, et al. Preventing chronic diseases: how many lives can we save? Lancet 2005;366: 1578-82.

7. Chakraborty N, Islam MA, Chowdhury RI, et al. Determinants of the use of maternal health services in rural Bangladesh. Health Promot Int 2003;18:327-37.

8. Fine LJ, Philogene GS, Gramling R, et al. Prevalence of multiple chronic disease risk factors. 2001 National Health Interview Survey. Am J Prev Med 2004;27(2 Suppl):18-24.

9. Alamian A, Paradis G. Correlates of multiple chronic disease behavioral risk factors in Canadian children and adolescents. Am J Epidemiol 2009;170:1279-89.

10. Tang S, Meng Q, Chen LC, et al. Tackling the challenges to health equity in China. Lancet 2008;372:1493-501.

11. Yang G, Kong L, Zhao W, et al. Emergence of chronic non-communicable diseases in China. Lancet 2008;372:1697-705.

12. Zhang $\mathrm{PH}$, Jiao SF, Zhou $\mathrm{Y}$, et al. Study on chronic disease related behavior and lifestyle in adults in Beijing, 2005. Zhonghua Liu Xing Bing XueZaZhi 2007;28:1162-6.
13. Lu LX, Yang L, Zhang D. Dynamic surveillance on behavior risk factors related to chronic diseases among adult residents in Xicheng District, Beijing, 2001-2007. Chin Prev Med 2008;9:1052-5.

14. Chinese Ministry of Health. Chinese health statistics summary: 2012 Beijing: Peking Union Medical College Press, 2012.

15. Appel LJ, Brands MW, Daniels SR, et al. Dietary approaches to prevent and treat hypertension: a scientific statement from the American Heart Association. Hypertension 2006;47:296-308.

16. Neter JE, Stam BE, Kok FJ, et al. Influence of weight reduction on blood pressure: a meta-analysis of randomized controlled trials. Hypertension 2003;42:878-84.

17. $\mathrm{Ng} \mathrm{N}$, Hakimi M, Santosa A, et al. Is self-rated health an independent index for mortality among older people in Indonesia? PLOS ONE 2012;7:e35308.

18. Girón P. Is age associated with self-rated health among older people in Spain? Cent Eur J Public Health 2012;20:185-90.

19. Ramkumar A, Quah JL, Wong T, et al. Self-rated health, associated factors and diseases: a community-based cross-sectional study of Singaporean adults aged 40 years and above. Ann Acad Med Singapore 2009;38:606-7.

20. Cecchini M, Sassi F, Lauer JA, et al. Tackling of unhealthy diets, physical inactivity, and obesity: health effects and cost-effectiveness. Lancet 2010;376:1775-84. 